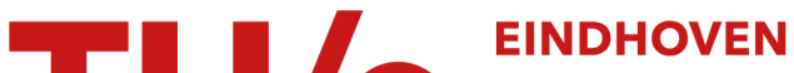 UNIVERSITY OF TECHNOLOGY
}

\section{Modeling, analysis and control of a variable geometry actuator}

\section{Citation for published version (APA):}

Evers, W. J. E., Knaap, van der, A. C. M., Besselink, I. J. M., \& Nijmeijer, H. (2008). Modeling, analysis and control of a variable geometry actuator. In Proceedings of the IEEE Intelligent Vehicles Symposium, 2008 (IV'08) Eindhoven, Netherlands, 4 - 6 June 2008 (pp. 251-256). Institute of Electrical and Electronics Engineers. https://doi.org/10.1109/IVS.2008.4621197

DOI:

10.1109/IVS.2008.4621197

Document status and date:

Published: 01/01/2008

\section{Document Version:}

Accepted manuscript including changes made at the peer-review stage

\section{Please check the document version of this publication:}

- A submitted manuscript is the version of the article upon submission and before peer-review. There can be important differences between the submitted version and the official published version of record. People interested in the research are advised to contact the author for the final version of the publication, or visit the $\mathrm{DOI}$ to the publisher's website.

- The final author version and the galley proof are versions of the publication after peer review.

- The final published version features the final layout of the paper including the volume, issue and page numbers.

Link to publication

\section{General rights}

Copyright and moral rights for the publications made accessible in the public portal are retained by the authors and/or other copyright owners and it is a condition of accessing publications that users recognise and abide by the legal requirements associated with these rights.

- Users may download and print one copy of any publication from the public portal for the purpose of private study or research.

- You may not further distribute the material or use it for any profit-making activity or commercial gain

- You may freely distribute the URL identifying the publication in the public portal.

If the publication is distributed under the terms of Article 25fa of the Dutch Copyright Act, indicated by the "Taverne" license above, please follow below link for the End User Agreement:

www.tue.nl/taverne

Take down policy

If you believe that this document breaches copyright please contact us at:

openaccess@tue.nl

providing details and we will investigate your claim. 


\title{
Modeling, Analysis and Control of a Variable Geometry Actuator
}

\author{
Willem-Jan Evers $^{\dagger \star}$, Albert van der Knaap ${ }^{\ddagger}$, Igo Besselink ${ }^{\dagger}$, Henk Nijmeijer ${ }^{\dagger}$ \\ $\dagger$ Eindhoven University of Technology, \\ Department of Mechanical Engineering, \\ $5600 \mathrm{MB}$ Eindhoven, The Netherlands \\ Fax: +31 402461418 \\ Email: W.J.E.Evers@tue.nl \\ Email: I.J.M.Besselink@tue.nl \\ Email: H.Nijmeijer@tue.nl \\ $\ddagger$ TNO Automotive, \\ Advanced Chassis and Transport Systems, \\ 5700 AT Helmond, The Netherlands \\ Fax: +314925665666 \\ E-mail: albert.vanderknaap@tno.nl \\ $\star$ Corresponding author.
}

\begin{abstract}
A new design of variable geometry force actuator is presented in this paper. Based upon this design, a model is derived which is used for steady-state analysis, as well as controller design in the presence of friction. The controlled actuator model is finally used to evaluate the power consumption under worst case conditions.
\end{abstract}

\section{INTRODUCTION}

The main function of a suspension system is to reduce the effect of environmental vibrations, e.g. to limit the transmissibility. This can be achieved with passive elements, e.g., springs and dampers, but also with (semi-) active elements. Herein, semi-active elements have the property that they can only dissipate energy, where active elements can also add energy to the suspension.

Semi-active suspensions consist of dampers with a variable damping constant. This variation can either be achieved mechanically, [12], or using so called "smart fluids". The latter can be roughly divided into two classes: magneto-rheological (MR) and electro-rheological (ER) dampers, [5], [7]. Semiactive suspensions generally have a low energy consumption (typically related to electric actuation of valve spools), while still giving improved performance in comparison to passive suspensions. However, the in theory obtainable performance is profoundly lower than what is obtainable with active suspensions, [4].

The best known active suspension element is probably the air spring, [3]. However, its bandwidth is typically so low that it cannot be used for much other than load leveling and load compensation. As such, it also consumes relatively little energy. Hydraulic actuators on the other hand can reach far higher bandwidths, see for example [1]. Another example of an active hydraulic suspension (in an automotive context) is the DaimlerChrysler Active Body Control system, [6], which reaches a bandwidth of up to $5 \mathrm{~Hz}$. However, hydraulic actuators generally have a high power consumption.

An alternative to lower the power consumption is the use of electro-magnetic actuators, [9], [13], as these have the capability to regenerate energy. Another alternative would be the use of a variable geometry (force) actuator, [15], [16].

In this paper a model is presented of the variable geometry actuator as described in [10]. It differs from the original design, as shown in Fig. 1, as it has a fixed spring. As such, the actuator has a higher achievable bandwidth, improved packaging options and a lower complexity. Besides the actuator model, an electric motor and friction model are included. Using these combined models, a cascaded control structure is designed and validated. Furthermore, the power consumption of the actuator is evaluated under worst-case conditions.

The paper is structured as follows. In sections two and three, a model is presented of the variable geometry actuator under consideration and of the used electric motor respectively. Section four discusses the actuator control strategy and in section five the actuator power consumption is analyzed. The paper ends with the conclusions and an outlook on future work.

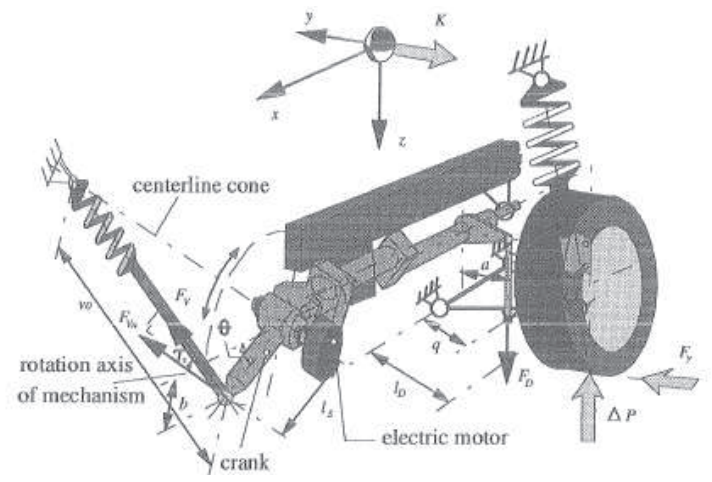

Fig. 1. The Delft Active Suspension (DAS), [15].

\section{FORCE ACTUATOR MODEL}

The variable geometry force actuator under consideration is inspired by the Delft Active Suspension [15], with the modification that it has a fixed spring [10], see Fig. 2. This is made possible, by using a flexible string that connects the spring to the outer end of a rotating arm. The benefits of this configuration over the conventional system with rotating spring include a higher achievable bandwidth (due to the lower inertia), better packaging (more compact system) and a reduced complexity (less pivots). 


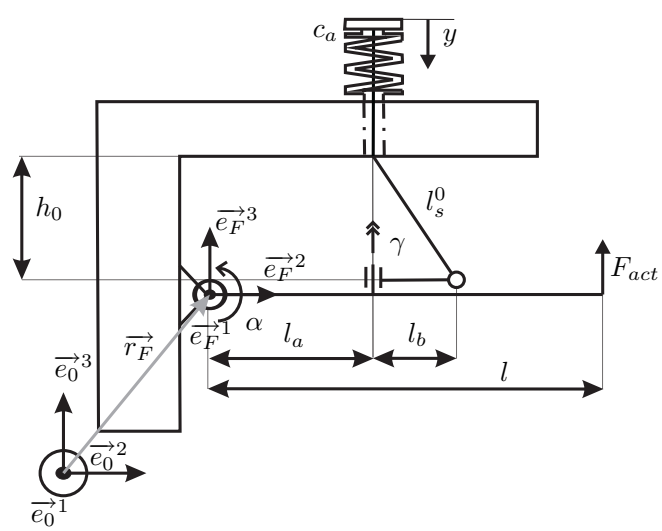

Fig. 2. Schematic representation of the variable geometry force actuator

The actuator consists of a wishbone with length $l$ which is connected to a frame with a joint that allows a rotation $\alpha$ around the $\overrightarrow{e_{F}}$-axis. Furthermore, attached to the wishbone at a distance $l_{a}$ from the joint is an electric motor, which driven direction $(\gamma)$ is perpendicular to the wishbone. The motor actuates an arm with length $l_{b}$, which is aligned with the $\overrightarrow{e_{F}} 1$-axis for $\gamma=0$. At the end of this arm, a string is connected through a rotational joint, which in turn passes through a hole in the frame. This hole coincides with the rotation axis of the electric motor, when the wishbone is aligned with the ${\overrightarrow{e_{F}}}^{2}$-axis (is horizontal) and is located at a distance $h_{0}$ above the wishbone. At the other end of this string a plate is attached that constraints a spring with stiffness $c_{a}$ and pre-tension $F_{s}^{0}$. The force within this spring gives rise to a force $F_{a c t}$ at the end of the wishbone. This is the actuator force, which varies for different values of $\alpha$ and $\gamma$.

The actuator is specifically designed for power efficiency. When the wishbone is horizontal $(\alpha=0)$, the outer end of the rotating arm describes a circle, of which the tangential velocity lies perpendicular to the spring force. As such, a fictitional cone is created with height $h_{0}$ and radius $l_{b}$, similar to that obtained by the Delft Active Suspension [15]. Consequently, the rotating arm can be rotated over any angle $\gamma$ without changing the spring elongation. So ideally, for $\alpha=0$, in the absence of friction and inertia effects, any rotation $\gamma$ (and thus any actuator force $F_{a c t}$ ) can be achieved without power usage. For any $\alpha \neq 0$ a disturbance moment $\left(M_{d}\right)$, induced by the spring force, acts on the electric motor which needs to be compensated to maintain a certain angle $\gamma$. For simulation purposes, the actuator force $F_{a c t}$ and the required motor moment $M_{r}$ are required as a function of the angles $\alpha$ and $\gamma$. Therefore, a kinematic model is derived next using Lagrange's equations of motion [8].

We take as generalized coordinates $\underline{q}=[\alpha, \gamma]$. The kinetic energy is given by

$$
T=\frac{1}{2} J_{w} \dot{\alpha}^{2}+\frac{1}{2} J_{r} \dot{\gamma}^{2}
$$

with $J_{w}$ and $J_{r}$ the inertia's of the wishbone and electric motor with rotating arm and reductor respectively.

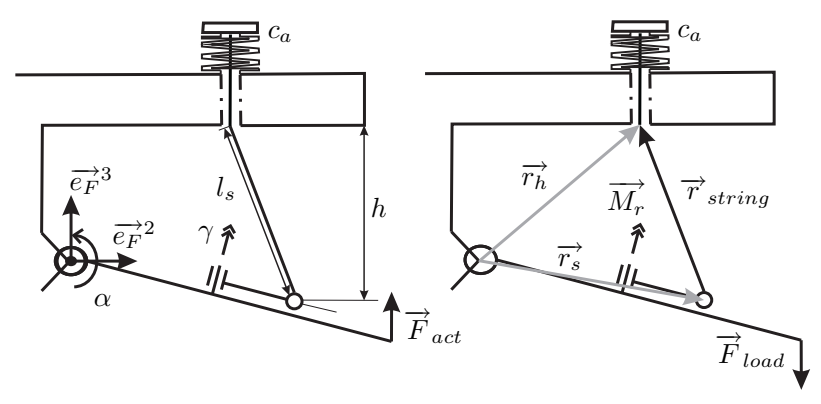

Fig. 3. Actuator spring elongation for $\alpha>0$ and $\gamma=90$ degrees.

From Fig. 3 it follows that the nonconservative forces can be written as

$$
\underline{Q}_{n c}=\left[\begin{array}{c}
-F_{\text {load }} l \cos \alpha \\
M_{r}
\end{array}\right],
$$

with $M_{r}$ the driving moment and $F_{\text {load }}$ the load from the suspended mass acting on the actuator.

The potential energy is given by

$$
\begin{aligned}
V & =\int_{0}^{\epsilon}\left(c_{a} y+F_{s}^{0}\right) d y \\
& =\frac{1}{2} c_{a} \epsilon^{2}+F_{s}^{0} \epsilon,
\end{aligned}
$$

where the spring compression $\epsilon$ is given by

$$
\epsilon=\underbrace{\left|\vec{r}_{\text {string }}\right|}_{l_{s}}-l_{s}^{0},
$$

$F_{s}^{0}$ is the spring pre-tension and $l_{s}^{0}$ is the length of the string for $\alpha=0$,

$$
l_{s}^{0}=\sqrt{h_{0}^{2}+l_{b}^{2}}
$$

Fig. 3 shows that

$$
\begin{aligned}
& \vec{r}_{\text {string }}=\vec{r}_{h}-\vec{r}_{s} \\
& =\left[\begin{array}{c}
-l_{b} \cos \gamma \\
l_{a}(1-\cos \alpha)-l_{b} \sin \gamma \cos \alpha \\
h_{0}-l_{b} \sin \gamma \sin \alpha-l_{a} \sin \alpha
\end{array}\right]^{T} \overrightarrow{\underline{e}_{F}} .
\end{aligned}
$$

So, from (4) and (6) it follows that

$$
\begin{aligned}
l_{s}^{2}=l_{b}^{2} & +l_{a}^{2}(1-\cos \alpha)+l_{a} l_{b} \sin \gamma(1-\cos \alpha)+\ldots \\
& +h_{0}^{2}-h_{0} \sin \alpha\left(l_{a}+l_{b} \sin \gamma\right) .
\end{aligned}
$$

Lagrange's equations of motion in the absence of constraints are (see for example [8]) given by

$$
\frac{d}{d t}\left(\frac{\delta T}{\delta \underline{\dot{q}}}\right)-\frac{\delta T}{\delta \underline{q}}+\frac{\delta V}{\delta \underline{q}}=\underline{Q}_{n c}^{T} .
$$

Herein,

$$
\frac{\delta V}{\delta \underline{q}}=\left[\begin{array}{c}
F_{s}^{0} a_{1} l_{s}^{-1}+c_{a} a_{1}\left(1-l_{s}^{0} l_{s}^{-1}\right) \\
F_{s}^{0} a_{2} l_{s}^{-1}+c_{a} a_{2}\left(1-l_{s}^{0} l_{s}^{-1}\right)
\end{array}\right]^{T},
$$

where

$a_{1}=l_{a}^{2} \sin \alpha+l_{a} l_{b} \sin \gamma \sin \alpha-h_{0} l_{a} \cos \alpha-h_{0} l_{b} \cos \alpha \sin \gamma$ $a_{2}=l_{a} l_{b} \cos \gamma(1-\cos \alpha)-h_{0} l_{b} \cos \gamma \sin \alpha$. 
Combining $(2,8,9)$, under steady-state conditions $(\ddot{\gamma}=\dot{\gamma}=$ $\ddot{\alpha}=\dot{\alpha}=0$ ) with the knowledge that $F_{a c t}=F_{\text {load }}$ it follows that

$$
F_{a c t}=-\frac{1}{l \cos \alpha}\left(F_{s}^{0} a_{1} l_{s}^{-1}+c_{a} a_{1}\left(1-l_{s}^{0} l_{s}^{-1}\right)\right) .
$$

Moreover, under steady-state conditions, the disturbance moment acting on the electric motor is given by

$$
M_{d}=-M_{r}=-F_{s}^{0} a_{2} l_{s}^{-1}-c_{a} a_{2}\left(1-l_{s}^{0} l_{s}-1\right) .
$$

The rotating arm with length $l_{b}$ is driven by an electric motor, which is connected to the arm through a reductor with gear ratio

$$
i=\frac{\omega_{m}}{\dot{\gamma}},
$$

where $\omega_{m}$ is the motor velocity. The arm, reductor and motor are assumed to behave as a single mass,

$$
J_{r} \ddot{\gamma}=M_{r}
$$

The actuator behavior is illustrated using the parameters given in Table I, where the spring pre-tension is determined

TABLE I

ACTUATOR EXAMPLE PARAMETERS

\begin{tabular}{lll}
\hline parameter & value & unit \\
\hline$c_{a}$ & 15.8 & $\mathrm{~N} / \mathrm{mm}$ \\
$m_{l}$ & 350 & $\mathrm{~kg}$ \\
$g$ & 9.81 & $\mathrm{~m} / \mathrm{s}^{2}$ \\
$h_{0}$ & 0.2 & $\mathrm{~m}$ \\
$l$ & 0.15 & $\mathrm{~m}$ \\
$l_{a}$ & 0.075 & $\mathrm{~m}$ \\
$l_{b}$ & 0.05 & $\mathrm{~m}$ \\
\hline
\end{tabular}

from the nominal design load $m_{l}$ as

$$
F_{s}^{0}=m_{l} g \frac{l}{l_{a}} \frac{l_{s}^{0}}{h_{0}} .
$$

Using these parameters and (11), the resulting steady-state actuator force can be plotted as a function of $\gamma$ and $\alpha$, see Fig. 4 (left). It can also be seen that the effective stiffness of the actuator $c_{e f f}$ (variation in actuator force as a function of $l \sin \alpha$ ) is overall much smaller than the stiffness of the spring $c_{a}$ and is a nonlinear function of $\alpha$ and $\gamma$, see Fig. 4 (right).
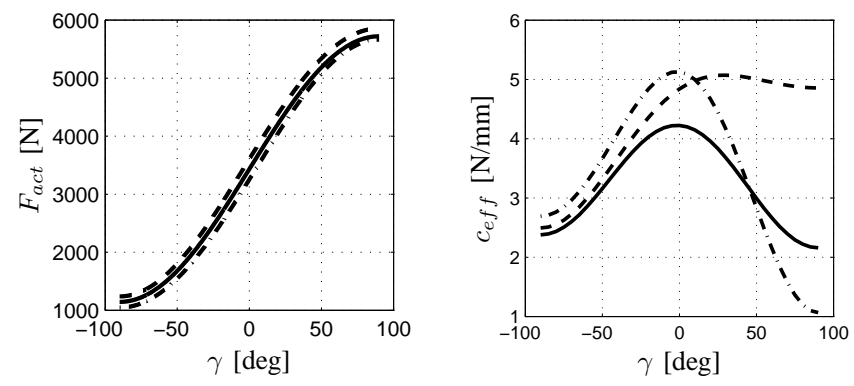

Fig. 4. Actuator force (left) and effective actuator stiffness (right) for $\alpha=0$ (solid), $\alpha=-15$ degrees (dashed) and $\alpha=15$ degrees (dashed-dotted).
It is also possible to visualize the characteristics of the resulting disturbance moment, see Fig. 5. The disturbance moment on the electric motor will be largest around $\gamma=0$ and will go to zero when $|\gamma|$ goes to 90 degrees. Moreover, it can be seen that due to the cone-principle, [15], no disturbance moment is present for $\alpha=0$.

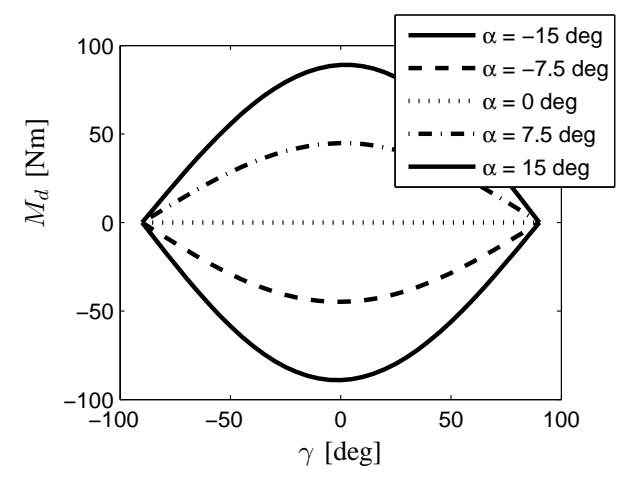

Fig. 5. Disturbance moment on electric motor for various $\alpha$.

If the system inertias and the actuator motions are sufficiently small, the actuator behavior will follow this kinematic model. In the remainder of this paper it is assumed that $J_{w}$ is negligible in comparison to the mass of the suspended mass. The remaining equation of motion is given by

$$
J_{r} \ddot{\gamma}=M_{r}+M_{d}
$$

\section{ELECTRIC MOTOR MODEL}

The electric motor itself typically has a far larger bandwidth than the total actuator assembly. For that reason it might be warranted to assume exact tracking of any reference moment $\left(M_{r}=M_{r}^{r e f}\right)$. However, in order to gain insight in the power consumption of the actuator, it is necessary to obtain both motor current and voltage. Furthermore, under extreme circumstances saturation of current and/or voltage may occur. Therefore, a basic dc-motor model is adopted for the dynamic analysis, see [11].

The actual motor current is described by

$$
L \frac{d I}{d t}=U-U_{e m f}-R I
$$

where

$$
U_{e m f}=K \omega_{m}
$$

$K$ is the motor constant, $I$ is the current, $U$ is the command voltage, $L$ is the motor inductance and $R$ is the motor resistance. Furthermore, the effective actuation moment is given by

$$
M=\left(M_{r e l}-M_{\text {fric }}\right) i,
$$

where the realized motor moment $M_{r e l}$ is given by

$$
M_{r e l}=K I
$$

and $M_{\text {fric }}$ is the friction moment of the motor and reductor, which has to be incorporated in the model as it will be an important source of energy dissipation. 
The friction moment is modeled using a LuGre model, [2] and is given by

$$
M_{\text {fric }}=s_{0} z+s_{1} \dot{z}+s_{2} \omega_{m}
$$

with $s_{0}, s_{1}, s_{2}$ friction parameters. Furthermore, $z$ can be seen as the deflection of tiny bristles in the contact patch and

$$
\dot{z}=\omega_{m}-\frac{\left|\omega_{m}\right|}{\beta} z .
$$

Moreover,

$$
\beta=\left\{F_{c}+\left(F_{s}-F_{c}\right) e^{-\left(\omega_{m} / \omega_{s}\right)^{2}}\right\} / s_{0},
$$

where $F_{c}, F_{s}$ and $\omega_{s}$ are parameters that determine the steady-state friction characteristic.

To illustrate the behavior of the friction model, we consider the friction parameters as given in Table II. These parameters are based upon motor specifications of a real dc-motor and our experience with this type of motor and reductor combination. Using these parameters, a simulation is run (stiff solver), with a sine-shaped velocity profile. The friction moment as a function of the rotational motor velocity is given in Fig. 6.

TABLE II

FRICTION EXAMPLE PARAMETERS

\begin{tabular}{lll}
\multicolumn{3}{c}{ Friction parameters } \\
\hline parameter & value & unit \\
\hline$s_{0}$ & 15 & $\mathrm{Nm}$ \\
$s_{1}$ & 0.1 & $\mathrm{Nms}$ \\
$s_{2}$ & $4.10^{-3}$ & $\mathrm{Nms}$ \\
$F_{c}$ & 0.2 & $\mathrm{Nm}$ \\
$F_{s}$ & 0.555 & $\mathrm{Nm}$ \\
$\omega_{s}$ & 11.8 & $\mathrm{rad} / \mathrm{s}$ \\
\hline
\end{tabular}

\begin{tabular}{lll}
\multicolumn{3}{c}{ Motor parameters } \\
\hline parameter & value & unit \\
\hline$K$ & 0.1 & $\mathrm{~V} / \mathrm{rad} / \mathrm{s}$ \\
$R$ & 0.13 & $\Omega$ \\
$L$ & $2.5 .10^{-4}$ & $\mathrm{H}$ \\
$i$ & 59 & - \\
$J_{r}$ & 0.70 & $\mathrm{kgm}^{2}$ \\
$I_{\max }$ & 75 & $\mathrm{~A}$ \\
$U_{\max }$ & 42 & $\mathrm{~V}$ \\
\hline
\end{tabular}

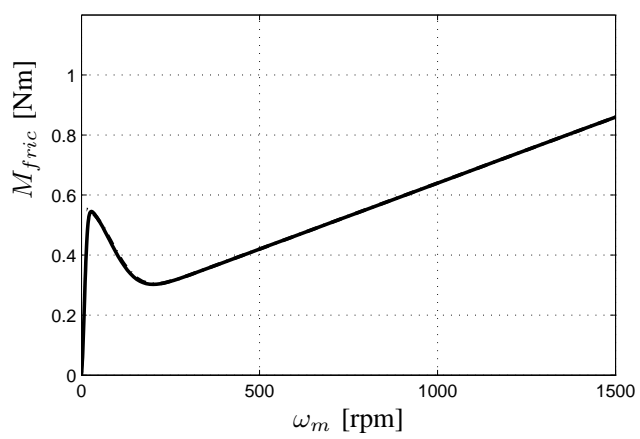

Fig. 6. Friction moment for sine-shaped velocity profile $(f=0.1 \mathrm{~Hz})$. Increasing velocity (solid) and decreasing velocity (dash-dotted).

As the actuator has restrictions on the maximum current and voltage, the dynamic behavior of the actuator will also be limited. The effect of these limitations can be visualized by looking at the maximum size of a sine-shaped reference that can be followed, without saturation. The reference is given by

$$
\gamma_{r e f}=A \sin (2 \pi f t)
$$

Moreover, the reference and its derivatives are constrained as

$$
\begin{aligned}
& \left|\gamma_{\text {ref }}\right| \leq \gamma_{\max } \\
& \left|\dot{\gamma}_{\text {ref }}\right| \leq \omega_{m}^{\max }=\frac{U_{\max }}{K i} \\
& \left|\ddot{\gamma}_{\text {ref }}\right| \leq \frac{M_{\max }-\left|M_{d}\right|}{J}=\frac{i\left(K I_{\max }-\left|M_{\text {fric }}\right|\right)-\left|M_{d}\right|}{J},
\end{aligned}
$$

by the physical limitations of the actuator with electric motor. So, the actuator's working range is intrinsically limited by three constraints.

Again consider the parameters as given in Table II and assume that $\gamma_{\max }=\pi / 2 \mathrm{rad}$. The working range of the actuator under these conditions, with $M_{\text {fric }}=0$ and $\alpha=0$ is represented in Fig. 7 by the area beneath the solid line. Furthermore, the three constraints are given by the dashed lines.

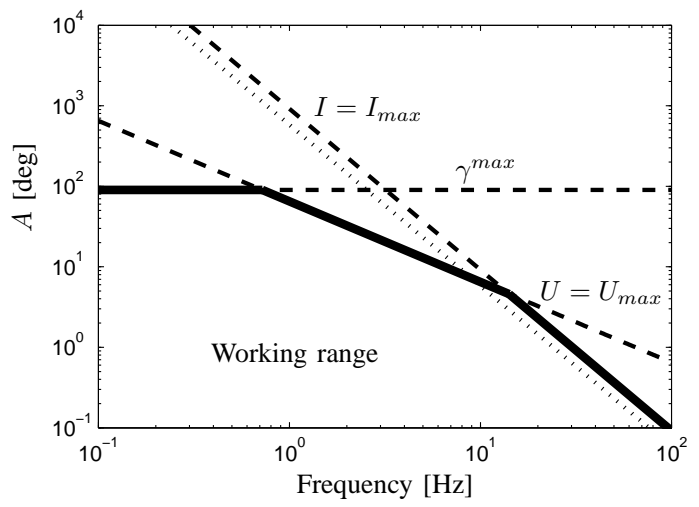

Fig. 7. Actuator working range (under the solid line) for $\alpha=0$ and $M_{\text {fric }}^{\max }=0$, constraints (dashed) and third constraint for $M_{\text {fric }}^{\max }=0.9$ $\mathrm{Nm}, \alpha=15$ degrees (dotted).

The first constraint, given by the horizontal line can be increased by increasing $\gamma^{\max }$. However raising it above 90 degrees will have no beneficial effect on the maximum actuator force. The second constraint, given by the dashed line with -1 slope, is determined by the maximum rotational velocity of the electric motor. It can be increased by increasing the maximum voltage $U_{\max }$. The third constraint, given by the dashed line with -2 slope, is determined by the maximum rotational acceleration of the electric motor. It can be increased by increasing the maximum current $I_{\max }$.

In reality the friction will be nonzero and also typically, there will be some rotation of the wishbone $|\alpha|>0$. These two conditions will give rise to a shift of the third constraint. From Fig. 6 it can be derived that the maximum friction moment for high rotational velocities is approximately 0.9 $\mathrm{Nm}$. When applying this friction moment and a maximum disturbance moment (for $\alpha=15$ degrees at $\gamma=0$ ), the worst-case working range limitation can be approximated. This approximation is given in Fig. 7 by the dotted line. 


\section{ACTUATOR CONTROL}

A cascaded control strategy is chosen to control the actuator. There is a motor controller, angle controller and force controller. The reason for choosing this strategy lies within the wish to constraint the reference angle to \pm 90 degrees. As a result, it is possible to use linear techniques to generate the reference angle as a function of the reference force and actual force. The three controller modules are shortly discussed in the following sections.

\section{A. Electric motor control}

The inner most control loop is that of the torque controller, see figure 8. It consists of a standard PI-controller with antiwindup,

$$
C_{m}=P_{m}+\left.\frac{I_{m}}{s}\right|_{U_{\max }},
$$

and a resistance feed forward,

$$
U_{m}^{f f}=R I_{\text {ref }}
$$

Herein, $P_{m}, I_{m}$ are control gains, the transfer function $H_{m}$ follows from (17),

$$
H_{m}=\frac{M_{r e l}(s)}{U(s)-U_{e m f}(s)}=\frac{K}{L s+R} .
$$

and $s$ is the Laplace variable. The controller brings the actual current close to the reference current and thus the realized moment $M_{r e l}$, see (19) and (20), close to the reference moment

$$
M_{\text {ref }}=K I_{\text {ref }}
$$

Moreover, both the maximum voltage and current are constraint (saturation blocks).

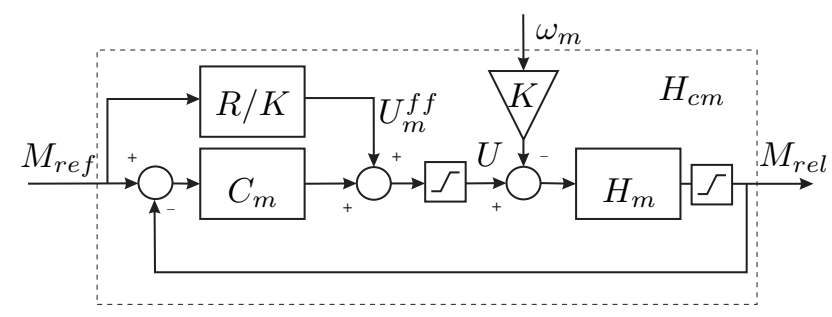

Fig. 8. Block-scheme of the motor control-loop.

\section{B. Angle control}

The second feedback loop is that of the angle controller, see Fig. 9. It consists of a lead-lag filter with integral action and anti-windup,

$$
C_{a}=P_{a}\left(\frac{s+D_{a}}{s+L_{a}}\right)+\left.\frac{I_{a}}{s}\right|_{I_{a}^{\max }} .
$$

The closed-loop system $H_{c m}$ is shown in Fig. 8 and $H_{\text {fric }}$ is defined by $(21,22,23)$.

The actuator hardware dynamics are modeled as

$$
H_{a}: \gamma=\frac{M+M_{d}}{J_{r} s^{2}},
$$

where $J_{r}$ is the inertia of the system (after the reductor), $M_{d}$ is given by (12) and $M$ is given by (19). Moreover, the relationship between $F_{a c t}$ and $\gamma$ is considered to be geometrically determined (no dynamics) and given by (11).

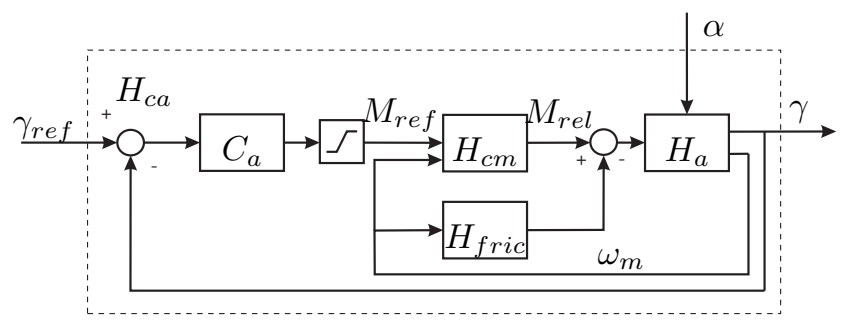

Fig. 9. Block-scheme of the angle control-loop.

\section{Force control}

The highest level control consists of the force controller. Its task is to minimize the difference between the generated actuator force and the reference actuator force. It consist of a feed forward part

$$
\begin{aligned}
\gamma_{r e f}^{f f} & =C_{f}^{f f}\left(F_{r e f}\right) \\
& =\sin ^{-1}\left(\frac{l l_{s}^{0} F_{r e f}}{l_{b} h_{0} F_{s}^{0}}-\frac{l_{a}}{l_{b}}\right),
\end{aligned}
$$

which prescribes the "right" reference $\gamma$ for $\alpha=0$ and a feedback part

$$
\begin{aligned}
\gamma_{r e f}^{f b} & =C_{f}\left(F_{r e f}-F_{a c t}\right) \\
C_{f} & =P_{f}\left(\frac{s+D_{f}}{s+L_{f}}\right)+\left.\frac{I_{f}}{s}\right|_{I_{f}^{\max }} .
\end{aligned}
$$

which corrects for disturbances $\alpha$. This way, it is possible to filter $\alpha$ such that high frequent influences are reduced (which is beneficial for power consumption). An alternative would be to adjust for $\alpha$ with feed forward. Furthermore, the total reference angle $\gamma_{\text {ref }}$ is bounded

$$
\gamma_{\text {ref }}=\left.\left(\gamma_{\text {ref }}^{f f}+\gamma_{\text {ref }}^{f b}\right)\right|_{-\pi / 2} ^{\pi / 2} .
$$

Using the controller parameters as given in Table III (which are a result of tuning), a $10 \mathrm{~Hz}$ reference force with a (maximum) amplitude of $200 \mathrm{~N}$ can be tracked reasonably well, see Fig. 11.

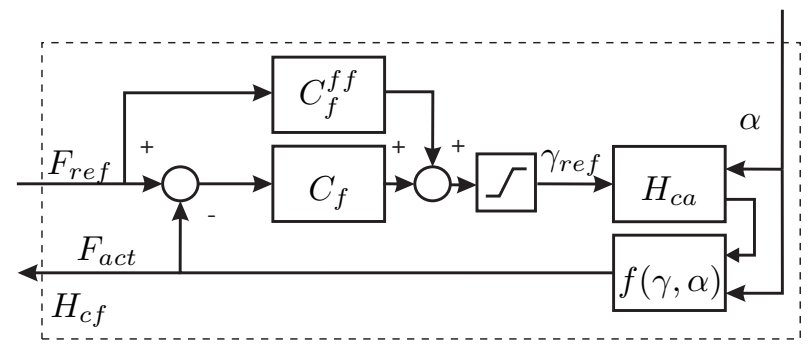

Fig. 10. Block-scheme of the force control-loop. 
TABLE III

CONTROLLER EXAMPLE PARAMETERS

\begin{tabular}{ll|ll}
\hline parameter & value & parameter & value \\
\hline$P_{a}$ & 1500 & $P_{f}$ & 0.00026 \\
$D_{a}$ & 4.49 & $D_{f}$ & 10.47 \\
$L_{a}$ & 94.25 & $L_{f}$ & 94.24 \\
$I_{a}$ & 4.49 & $I_{f}$ & 0.0063 \\
$I_{a}^{\max }$ & 6 & $I_{f}^{\max }$ & 1.57 \\
\hline
\end{tabular}
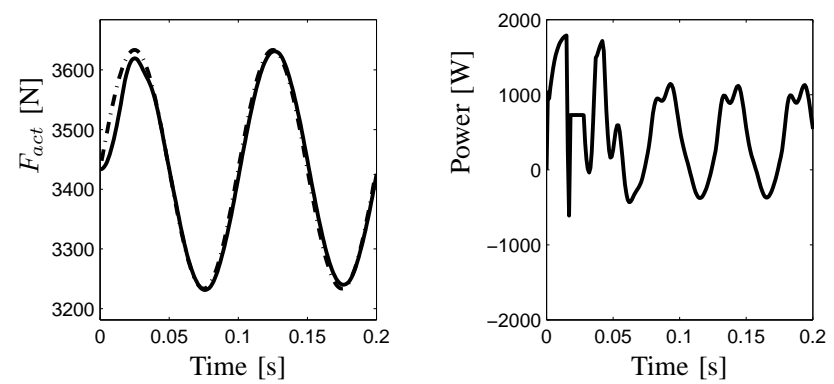

Fig. 11. Tracking a sine-shaped force reference with a $200 \mathrm{~N}$ amplitude and a frequency of $10 \mathrm{~Hz}$ for $\alpha=0$, when starting from standstill. Simulated actuator force (solid) and reference force (dash-dotted) (left) and simulated power consumption (right).

\section{ACtUATOR POWER CONSUMPTION}

In order to get an idea of the worst case power consumption of the actuator several simulations are performed. First, for $\alpha=0$, several sine shaped force references are tracked. Herein the amplitude and frequency of the sines is varied. The maximum amplitude $A$ for a certain frequency is obtained from Fig. 7. The results are given in Fig. 12 both for simulations with (left) and without friction (right). It can be seen that the mean power consumption rises as the frequency of the sine rises. In other words, high frequent reference signals have a relatively large power consumption. Furthermore, it can be seen that friction effects account for the major part of the used power below $10 \mathrm{~Hz}$.
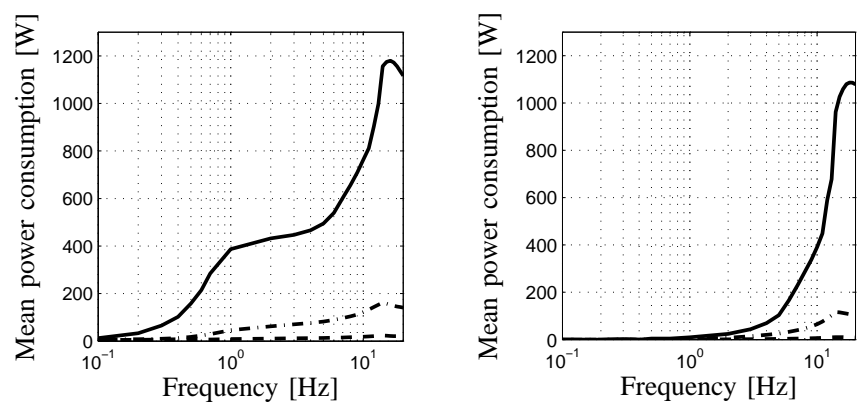

Fig. 12. Actuator power consumption for $\alpha=0$, when tracking sines of varying frequency and various amplitudes: maximum amplitude $A$ (solid); $A / 3$ (dash-dotted); and $A / 10$ (dotted). Simulations with friction (left) and without friction (right).

On the other hand, from simulations using the maximum amplitude $A$ and various fixed $\alpha$, it followed that the influence of $\alpha$ on the power consumption under extreme circumstances is limited.

\section{CONCLUSIONS AND FUTURE WORK}

A model has been derived for the variable geometry actuator under consideration. It is used, in combination with an electric motor model and LuGre friction model, to design a cascaded controller. Using a simulation example it is shown that the controlled actuator can easily track a $10 \mathrm{~Hz}$ sine with an amplitude of $200 \mathrm{~N}$. Furthermore, the power consumption of the actuator under worst case conditions is evaluated. From this evaluation it follows that high frequent force reference signals have a relatively high influence on the power consumption. Moreover, it is shown that the influence of friction below $10 \mathrm{~Hz}$ is substantial. Still, the worst case power consumption is much lower than that of hydraulic actuators under the same conditions, [6], [14].

Future research will focus on implementation of this actuator in (full) vehicle simulation models and design of suitable active suspension vehicle controllers. This way, the added value of such an actuator can be evaluated under reallife conditions. Furthermore, experimental validation of the variable geometry actuator might also become a topic when the added value is proven by vehicle simulations.

\section{REFERENCES}

[1] A. Alleyne and R. Liu. "A simplified approach to force control for electro-hydraulic systems". Control Engineering Practice, 8, pp 13471356,2000

[2] C. Canudas de Wit, K. Olsson, K.J. Aström and P. Lischinsky. ”A New Model for Control of Systems with Friction". IEEE Transactions on Automatic Control, 40(3), pp 419-425, 1995.

[3] Ballo, I. "Properties of air spring as a force generator in active vibration control systems". Vehicle System Dynamics, 35(1), pp 6772, 2001.

[4] Fischer, D. and Isermann, R. "Mechatronic semi-active and active vehicle suspensions". Control Engineering Practice, 12, pp 13531367, 2004.

[5] Han, S.S., Choi, S.B., Park, J.S., Kim, J.H. and Choi, H.J. "Robust sliding mode control of an electrorheological suspension system with parameter perturbations". International Journal of Vehicle Design, 33(1-3), pp 279-295, 2003.

[6] Heißing, B. and Ersoy, M. "Fahrwerkhandbuch". pp 533-536, Friedr. Vieweg \& Sohn Verlag 2007.

[7] Hrovat, D. "Survey of advanced suspension developments and related optimal control applications". Automatica, 33(10), pp 1781-1817, 1997.

[8] Huston, R.L. "Multibody dynamics". ISBN: 0-409-90041-9, Butterworth-Heinemann, London, 1995.

[9] http://www.bose.com/suspension, October, 2007.

[10] Nederlandse organisatie voor toegepast natuurwetenschappelijk onderzoek TNO, "Anti-roll/pitch system for use in a vehicle and vehicle equiped with such system". International patent, number WO 2006/019298 A1, February, 2007.

[11] E. Mablekos. Electric machine theory for power engineers, ISBN: 006044149-6. Harper\&Row Publishers, New York, 1980.

[12] Muijderman, J.H.E.A. "Flexible objective controllers for semi-active suspensions with preview". PhD. Thesis, Eindhoven University of Technology, 1997.

[13] Nakano, K. and Suda, Y. "Combined Type Self-Powered Active Vibration Control of Truck Cabins". Vehicle System Dynamics, 41(6), pp 449-473, 2004.

[14] Sharp, R.S. and Crolla, D.A. "Road Vehicle Suspension System Design - a review". Vehicle System Dynamics, 16, pp 167-192, 1987.

[15] Venhovens, P.J.Th. and Knaap, A.C.M. van der "Delft Active Suspension (DAS). Background Theory and Physical Realization". Smart Vehicles, ed. Pauwelussen, J.P. and Pacejka, H.B., pp 139-165, Taylor \& Francis 1995.

[16] Watanabe, Y. and Sharp, R.S. "Mechanical and Control Design of a Variable Geometry Active Suspension System". Vehicle System Dynamics, 32, pp 217-235, 1999. 